\title{
SIMULAÇÃO EXPLORATÓRIA dOS EFEITOS DAS MARÉS NA CIRCULAÇÃO E TRANSPORTE HIDRODINÂMICOS DA BACIA DO PINA
}

\author{
Alex Maurício Araújo e Thiago Tinoco Pires \\ Departamento de Engenharia Mecânica - UFPE - Grupo de Mecânica dos Fluidos Ambiental - GMFA/UFPE \\ Av. Acadêmico Hélio Ramos, S/N, CEP 50740-530, Recife/ PE - Brasil \\ 49ama@npd.ufpe.br
}

\section{RESUMO}

Um sistema computacional bidimensional integrado na profundidade (2DH), adaptado e desenvolvido pelo GMFA/UFPE, foi usado para tentar simular a circulação e o associado transporte hidrodinâmico induzido pelas marés na bacia do Pina, componente do sistema estuarino da cidade do Recife-PE. O propósito desse estudo foi o de avaliar alterações, ainda em caráter exploratório, no padrão da circulação e do transporte, causados por diferentes amplitudes de marés (sizígia e quadratura). Em todas as simulações foram utilizados treze instantes de tempo com intervalos de 1 hora para a observação dos campos de velocidades e de transporte, produzidos durante um ciclo completo da maré correspondente. Como resultado qualitativo geral, obteve-se configurações de circulação hidrodinâmica indicativas de afluxos e refluxos pela bacia de acordo com a situação da maré. Na simulação do transporte hidrodinâmico, a configuração geral dos resultados obtidos, no caso de lançamento de um poluente fictício no contorno forçante de maré, ratificou as respostas do modelo hidrodinâmico através de uma dinâmica de manchas de concentrações indicativas de intenso espalhamento pela maré, comparativamente com os resultados dos lançamentos pelo contorno de fluxo nulo.

\section{INTRODUÇÃO}

O prognóstico das variações das elevações do nível d'água e das associadas correntes e transporte produzidos em corpos d'água das regiões costeiras deve constituir-se numa tarefa preliminar dos estudos de impacto ambiental relacionados com várias possíveis intervenções de engenharia.

No passado, o tratamento desses problemas apoiava-se quase exclusivamente nos resultados obtidos com os chamados modelos físicos. Porém durante as duas últimas décadas, o advento dos modernos computadores e sistemas tem levado ao desenvolvimento e utilização dos modelos matemáticos para a solução de fluxos in- duzidos por efeito de maré. Atualmente a grande maioria destes modelos em uso prático são bidimensionais horizontais e calculam velocidades médias na profundidade do corpo d'água (2DH). Neves (1985), Rosman (1987), Araújo (1993), Borche (1996).

Uma das principais dificuldades na aplicação prática desses modelos diz respeito à falta de dados de campo como registros de correntes, batimetrias, estudos de dispersão espacial de poluentes, conhecimento de material de fundo para especificação de coeficiente de atrito, dentre outros. Nesses casos, este método de trabalho deve vir a ser utilizado como uma ferramenta exploratória de apoio visando minimizar o esforço de um plano de levantamento de dados de campo, item fundamental no detalhamento de programas de monitoramento ambiental para o corpo d'água em estudo.

\section{DESCRIÇÃO DA BACIA DO PINA}

A bacia do Pina é um ambiente dinâmico do ponto de vista hidrográfico com características estuarinas sujeitas à ação das marés provenientes do Porto do Recife e às alterações ambientais devido aos despejos de efluentes domésticos e industriais nos seus rios formadores (Tejipió, Pina, Jordão e Capibaribe), Feitosa (1988). Durante a estação do verão, época mais crítica do ponto de vista ambiental, a contribuição das vazões dos rios fica minimizada relativamente à das águas do mar, Araújo (1993).

Na região estudada, as marés são do tipo semi-diurno e sua altura máxima, em relação ao Porto do Recife, nas marés de sizígias pode alcançar na preamar $2,70 \mathrm{~m}$ e mínima na baixa-mar $-0,20 \mathrm{~m}$, apresentando portanto uma amplitude máxima da ordem de $2,90 \mathrm{~m}$.

Ela está situada na parte interna do Porto do Recife, em plena zona urbana da cidade e separada do Oceano Atlântico por meio de um dique natural, o qual impede o contato direto de suas águas com o mesmo. Possui uma extensão de 
aproximadamente $3,6 \mathrm{~km}$ e larguras variáveis, sendo a mínima de $0,26 \mathrm{~km}$, e a máxima de $0,86 \mathrm{~km}$, perfazendo uma área total de aproximadamente $2,02 \mathrm{~km}^{2}$. Ver Figura 1.

\section{USOS POTENCIAIS DA BACIA}

Do ponto de vista da engenharia da qualidade das águas, pode-se afirmar que atualmente os principais usos-benefícios dos recursos hídricos da área da bacia do Pina, são por ordem: transporte e diluição dos efluentes sanitários e industriais lançados diretamente ou afluindo para a bacia através dos seus corpos d'água formadores; navegação e atracação de embarcações; uso estético, além de sua grande importância sócio-econômico em função das atividades pesqueiras realizadas pela população de baixa renda circunvizinha.

Ultimamente, a bacia vem sendo alvo de intensa poluição. É visível a presença de manchas de óleo na superfície da água e lançamentos diretos de esgotos domésticos e industriais sem tratamento prévio. A intensificação do uso na modalidade transporte e diluição de efluentes limita e restringe a expansão dos usos de navegação, pesca, lazer, esportes náuticos e principalmente o uso estético daquela belíssima coleção d'água.

Um corpo d'água com grande potencial biológico e produtivo, e grande importância sócio econômica, deve ser considerado área privilegiada e ter um uso mais adequado e que traga benefícios mais vantajosos. Em especial, a cidade do Recife possui um grande potencial a ser explorado na área de lazer aquático. Além das praias, tradicional atração turística, o aspecto fluvial estuarino da cidade do Recife deve ser considerado, estudado e planejado racionalmente o seu uso de modo a que se possa explorar devidamente todo o seu potencial.

O planejamento de um pólo de turismo e lazer aquático na bacia do Pina fundamenta-se na melhoria da qualidade de vida dos habitantes da cidade do Recife e nos pressupostos macroeconômicos de que o turismo em Pernambuco está situado entre as suas maiores vocações econômicas. Sua concepção baseia-se na valorização da beleza paisagística e nos seus atributos de vir a ser um local ideal para a promoção de eventos ligados ao lazer e esportes náuticos (remo, vela, esqui aquático, canoagem, etc.), devendo ser sua sustentabilidade usufruída, protegida e garantida simultaneamente.

\section{MODELO HIDRODINÂMICO}

\section{Metodologia utilizada}

O sistema computacional utilizado neste trabalho tem como base os modelos matemáticos contínuos fundamentados nas equações de águas rasas, que compõem uma classe de problemas dinâmicos de mecânica dos fluidos/hidráulica caracterizada por apresentar uma relação comprimento de onda do forçante, no mínimo, vinte vezes a profundidade média do corpo d'água modelado.

Grande parte dos corpos d'água rasos pode ser bem representado por um modelo bidimensional (2D) no plano horizontal (2DH). Para isso é preciso que as escalas verticais sejam muito menores que as horizontais, e que a coluna d'água seja bem misturada, isto é, haja pouca ou nenhuma estratificação vertical.

É possível, com estas condições, a integração na profundidade das equações (3D) tridimensionais com o uso da regra de Leibnitz para diferenciação parcial de uma integral entre limites variáveis e adequadas condições de contorno na superfície livre e fundo do corpo d'água, transformando-as em um sistema (2D) em que os valores das variáveis são médias obtidas da sua distribuição vertical real.

Basicamente as equações governantes (2D) do problema hidrodinâmico podem ser escritas em notação indicial $(i, j=1,2)$ como:

$$
\begin{gathered}
\frac{\partial \mathrm{H}}{\partial \mathrm{t}}+\frac{\partial\left(\mathrm{HU}_{\mathrm{i}}\right)}{\partial \mathrm{x}_{\mathrm{i}}}=0 \\
\frac{\partial \mathrm{U}_{\mathrm{i}}}{\partial \mathrm{t}}+\mathrm{U}_{\mathrm{j}} \frac{\partial \mathrm{U}_{\mathrm{i}}}{\partial \mathrm{x}_{\mathrm{j}}}=-\mathrm{g} \frac{\partial \xi}{\partial \mathrm{x}_{\mathrm{i}}}+\frac{1}{\mathrm{H}} \frac{\partial}{\partial \mathrm{x}_{\mathrm{j}}}\left\{\mathrm { H } \left[\mathrm { K } _ { \mathrm { ij } } \left(\frac{\partial \mathrm{U}_{\mathrm{i}}}{\partial \mathrm{x}_{\mathrm{j}}}\right.\right.\right. \\
\left.\left.\left.+\frac{\partial \mathrm{U}_{\mathrm{j}}}{\partial \mathrm{x}_{\mathrm{i}}}\right)\right]\right\}+\frac{1}{\rho \mathrm{H}}\left(\tau_{\mathrm{i}}\right)_{\mathrm{F}}^{\mathrm{S}}
\end{gathered}
$$

onde (1) é a equação da continuidade e (2) é a equação da conservação da quantidade de movimento. Adotou-se a seguinte convenção nestas equações: $\mathrm{H}$ - profundidade atual do nível d'água, $U_{\mathrm{i}}$ - velocidade em x ou y, g - aceleração da gravidade, $\xi$ - elevação atual a partir do nível médio, $\mathrm{K}_{\mathrm{ij}}$ - tensor dos coeficientes de viscosidade turbulenta horizontal, $\rho$ - massa específica de referência 


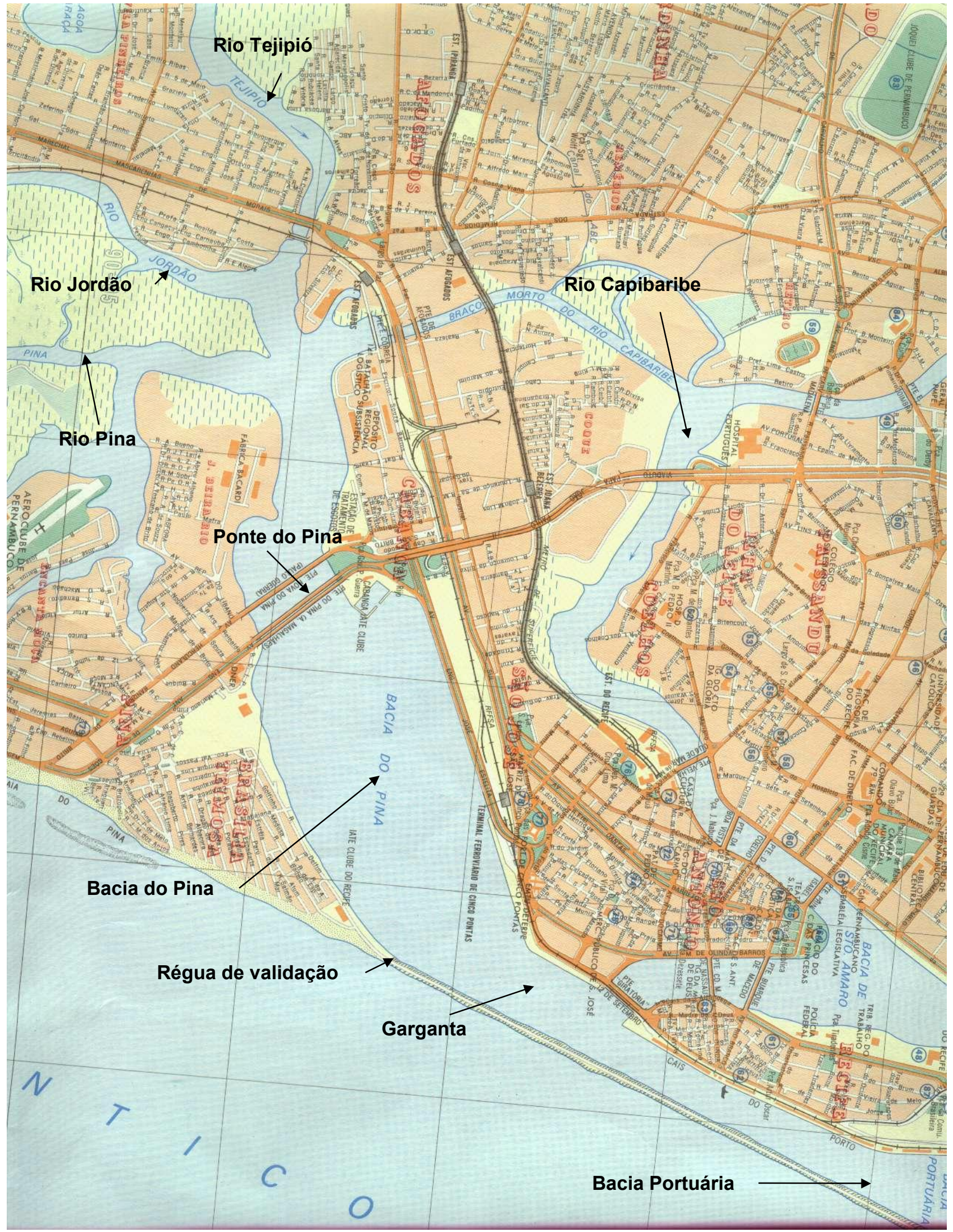

Figura 1. Localização da Bacia do Pina no Estuário do Recife. 
fluido função da temperatura, $\left(\tau_{\mathrm{i}}\right)_{\mathrm{F}}^{\mathrm{S}}$ - tensões na superfície livre $(S)$ e no fundo $(F)$ a serem parametrizadas.

As principais hipóteses assumidas na formulação das Equações (1) e (2) são as de que a pressão atmosférica e a massa específica do fluido são constantes. A discretização e formulação numérica daquelas equações constituem o modelo hidrodinâmico ou de circulação. No sistema computacional usado, o coeficiente de viscosidade turbulenta horizontal é parametrizado no programa através de expressão que leva em conta as profundidades e velocidades de cisalhamento atual em cada elemento. $\mathrm{O}$ coeficiente de atrito de fundo em cada nó é calculado em função da profundidade atual e da altura de rugosidade nodal. Por falta de dados de campo mais detalhados, adotou-se um único valor de altura de rugosidade nodal $(0.03 \mathrm{~m})$, valor este baseado em Abbot e Basco (1989) para fundo de leito com transporte de areia.

No espaço, o modelo hidrodinâmico usa elementos quadráticos (triângulos ou quadriláteros quaisquer). No modelo numérico usou-se o método dos resíduos ponderados Galerkin na obtenção das equações de forma integral, na chamada formulação fraca ou residual ponderada. Fundamentalmente a aproximação por elementos finitos objetiva substituir as integrais no domínio pela soma das integrais aplicadas em cada elemento finito da discretização do domínio total. Para maiores detalhes da sequência de procedimentos e equações necessários à obtenção das formulações discretas, consultar Araújo e Medeiros (1992) e Araújo (1993).
A implementação computacional da formulação discreta foi feita usando-se linguagem Fortran no sistema Vax 8700/VMS versão 5.4-1 do NPD (Núcleo de Processamento de Dados) - UFPE.

\section{Dados do problema}

A projeção horizontal da bacia do Pina foi discretizada, para efeito de cálculo, por uma malha constituída por elementos finitos quadráticos, indicados na Figura 2.

Por ainda não se dispor de um gerador de malhas, usou-se o processo de tentativas e erros para a definição da malha final. Esta ficou composta de: 51 elementos finitos com 239 nós, sendo 9 nós no contorno aberto (forçante de maré da bacia portuária) e 59 nós no contorno fechado, sendo 7 desses pertencentes à fronteira da bacia com a foz comum dos rios do estuário (adotado como contorno de fluxo nulo). Apresenta uma distância máxima entre nós de $410 \mathrm{~m}$ e mínima de $50 \mathrm{~m}$.

O intervalo de tempo de cálculo usado foi de $600 \mathrm{~s}$. Com esta discretização, o número de Courant máximo possível seria de 2.6, e seu valor médio nodal é menor que 1.0 .

Os dados da batimetria da bacia, esquematizados na Figura 3, foram obtidos através de levantamentos efetuados pela Marinha do Brasil contidos em mapa da área do Porto do Recife. Atualmente eles estão desatualizados, servindo apenas de referência qualitativa.

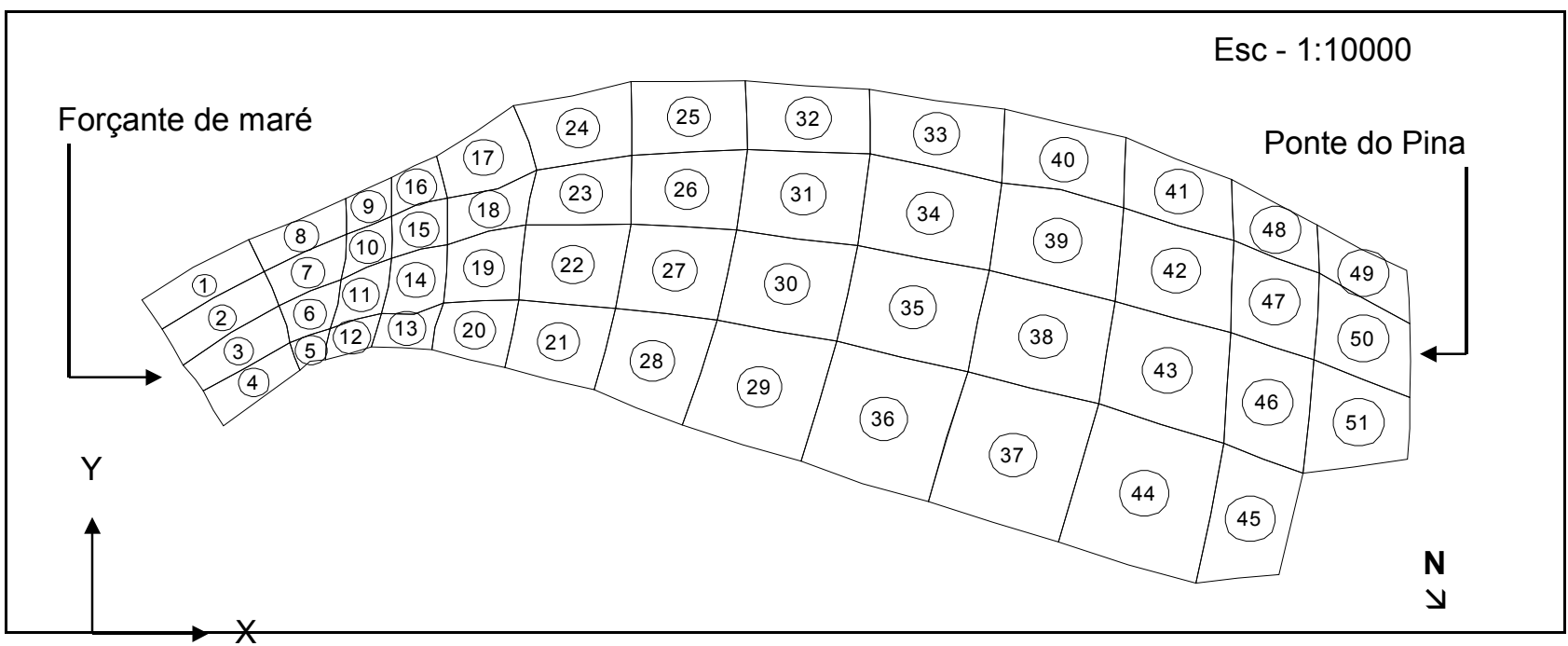

Figura 2. Discretização de elementos finitos quadráticos. 


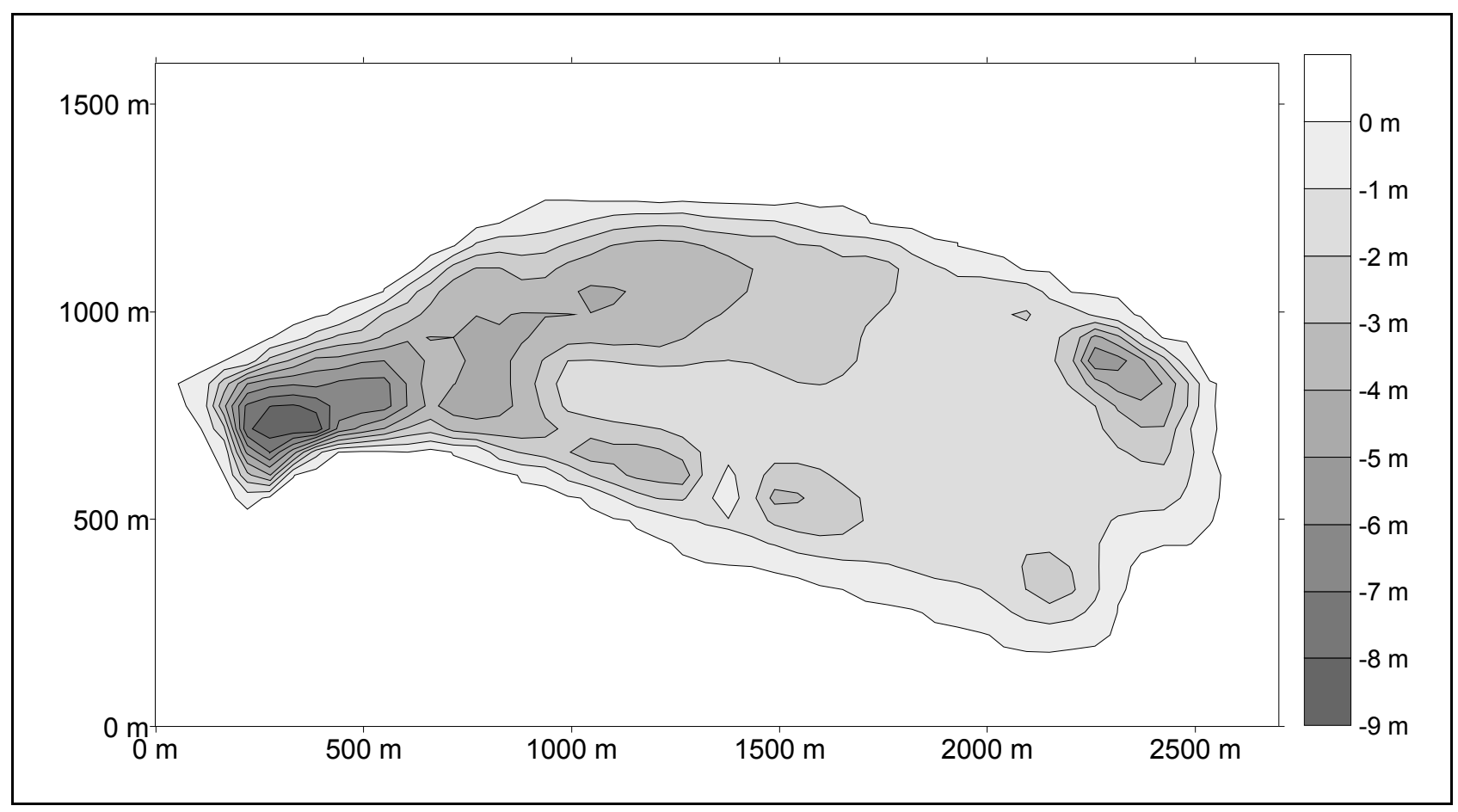

Figura 3. Batimetria da Bacia do Pina.

No forçante de maré foram usados valores transientes de elevações com variação senoidal. Adotou-se duas marés típicas com os seguintes parâmetros característicos: amplitudes de $0,8 \mathrm{~m}$ (quadratura) e 2,2 m (sizígia); período de $44600 \mathrm{~s}$; e fase de 1,5708 rad. Nesta aplicação exploratória, ainda não foi considerada a ação do forçante de ventos na superfície livre do corpo d'água em estudo. Estipulou-se que o sistema computacional apresentasse os resultados de saída a cada hora, durante um tempo de simulação de 432000 s equivalentes à aproximadamente dez períodos de maré.

\section{Descrição dos campos de velocidade obtidos}

Dos treze instantes de tempo com intervalos de $1 \mathrm{~h}$ selecionados para a representação do período completo da maré correspondente, adotouse para a descrição dos resultados obtidos os instantes 1 (preamar), 4 (nível médio), 8 (baixa-mar), 11 (nível médio) e 13 (preamar), durante o ciclo de maré correspondente ao sétimo período de simulação.

Maré de sizígia - No instante 1, mostrado na Figura 4, a bacia principal apresenta um fluxo discreto ocorrendo a presença de células de circulação na margem superior da figura. O escoamento na garganta se apresenta com características turbulentas, indicadas por fluxos com sentidos e magnitudes variadas.

Com o nível das águas se aproximando do nível médio, no instante 4 mostrado na Figura 5, o fluxo de maré efluente se apresenta em toda a bacia com advecção bem definida, notando-se um efeito de jato na garganta da bacia.

No instante 8 mostrado na Figura 6, ocorre a inversão total do sentido do fluxo, que passa a ser afluente à bacia do Pina.

Com o nível da maré se aproximando novamente ao nível médio, no instante 11 mostrado na Figura 7, observa-se um aumento de advecção na região da garganta.

De volta a preamar, o instante 13 apresentou um padrão de movimento assemelhado ao do instante 1, mostrado na Figura 4.

Maré de quadratura - No instante 1 , indicado na Figura 8, observa-se na garganta um escoamento complexo, com a presença de vórtices. No resto do campo de escoamento as magnitudes das velocidades são baixas.

No instante 4, mostrado na Figura 9, bem próximo do nível médio desta maré, a magnitude do fluxo aumenta, apresentando características de um escoamento comandado por advecção em toda a bacia. 


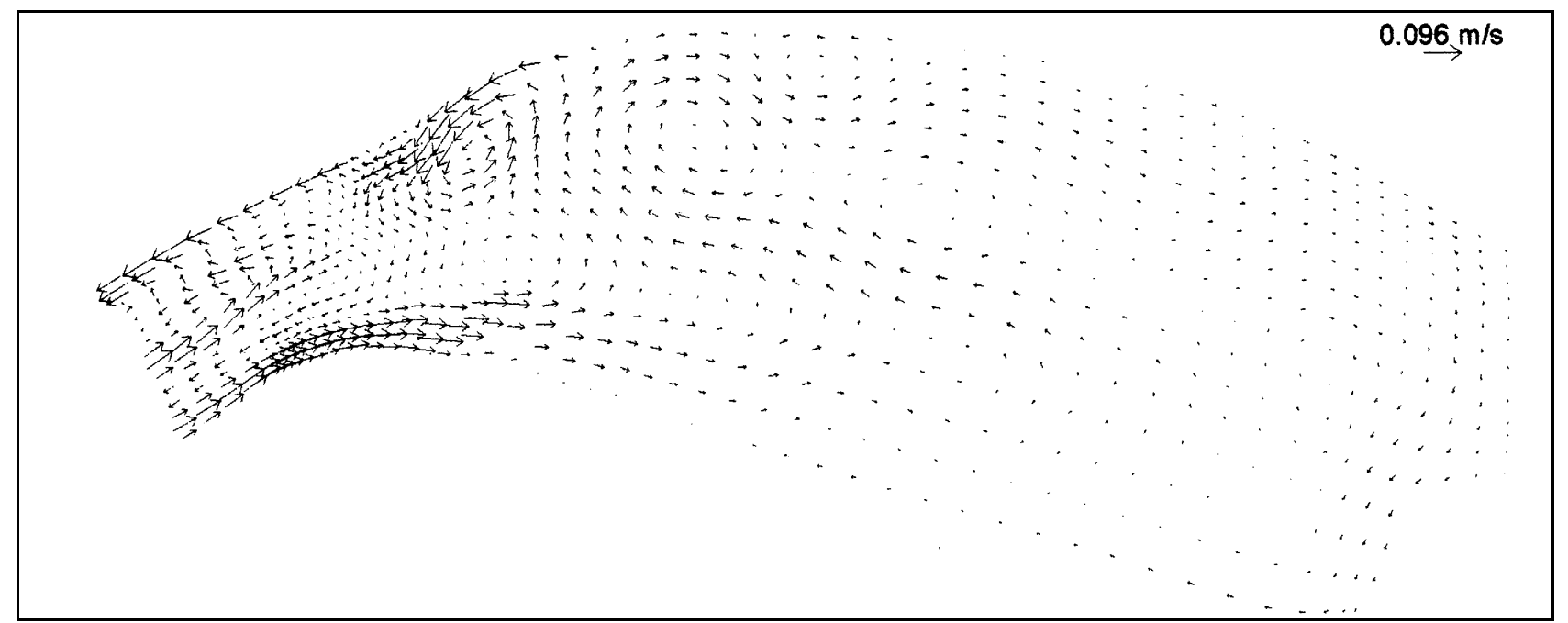

Figura 4. Configuração dos Vetores Velocidade no instante 1.

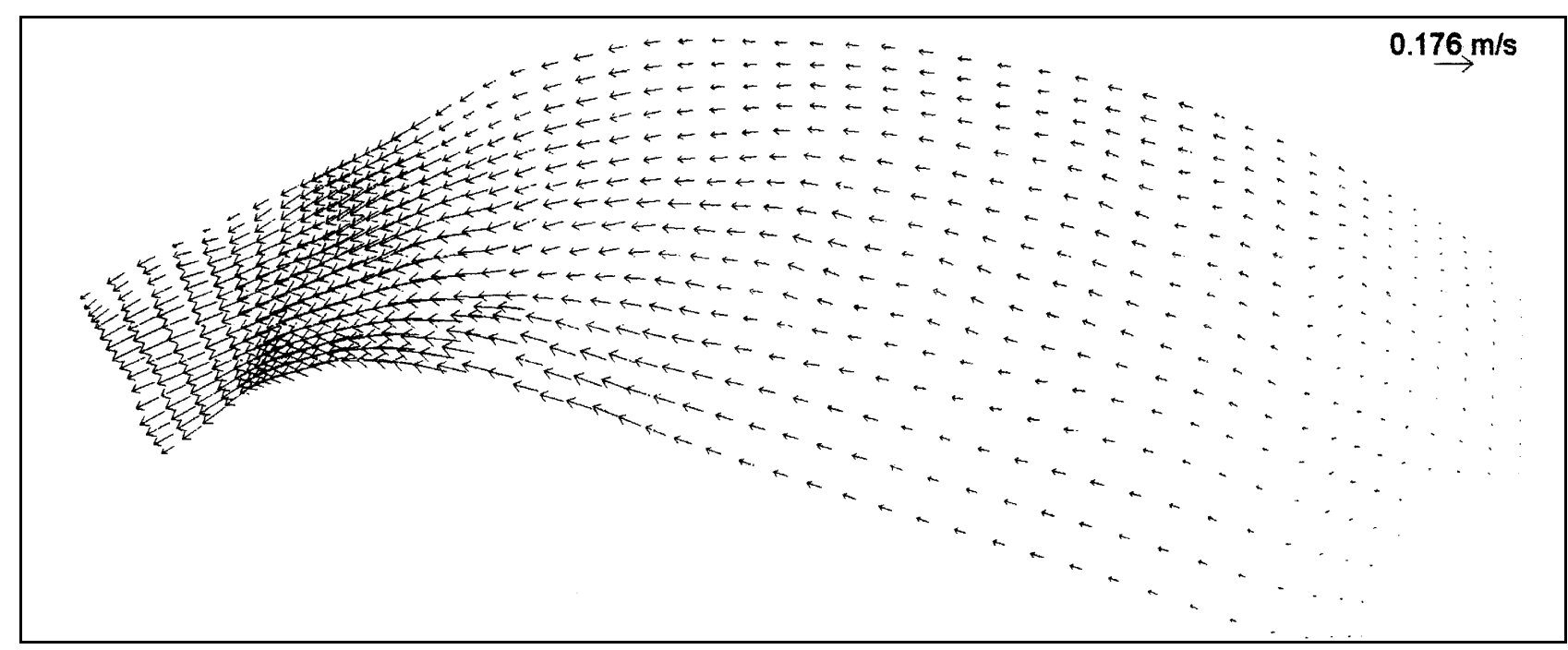

Figura 5. Configuração dos Vetores Velocidade no instante 4.

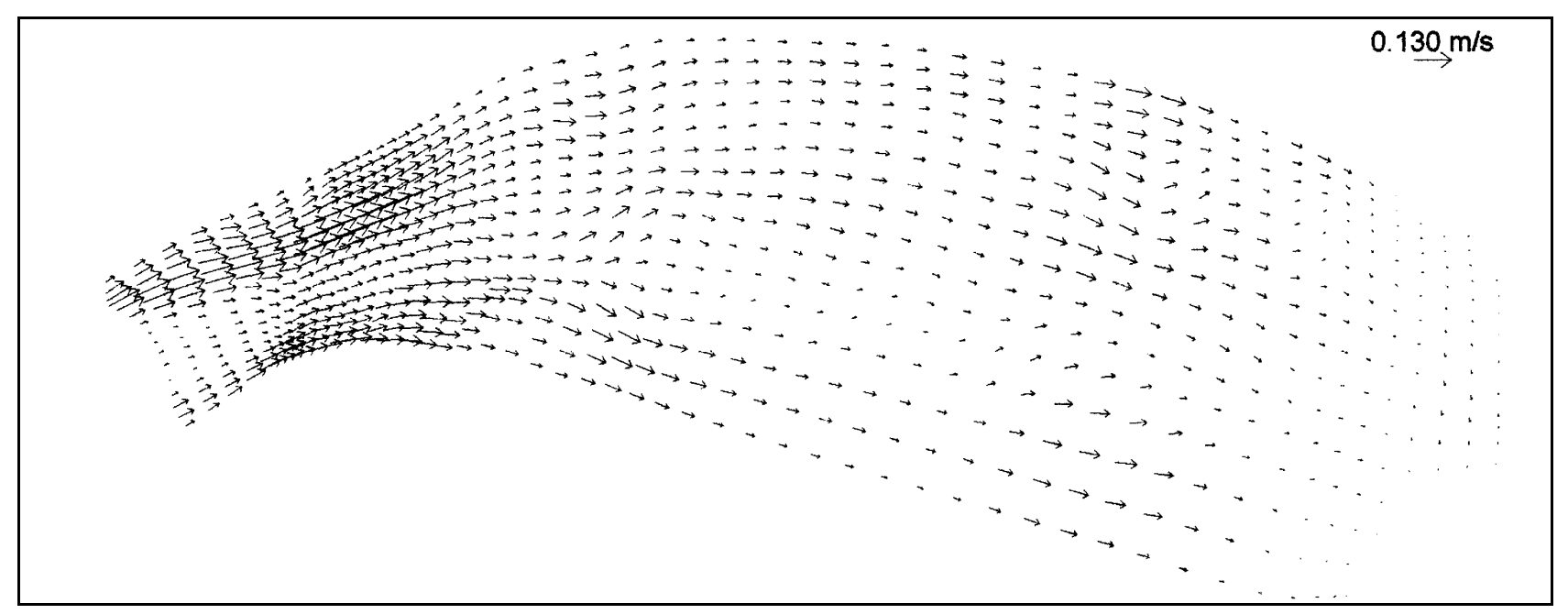

Figura 6. Configuração dos Vetores Velocidade no instante 8. 


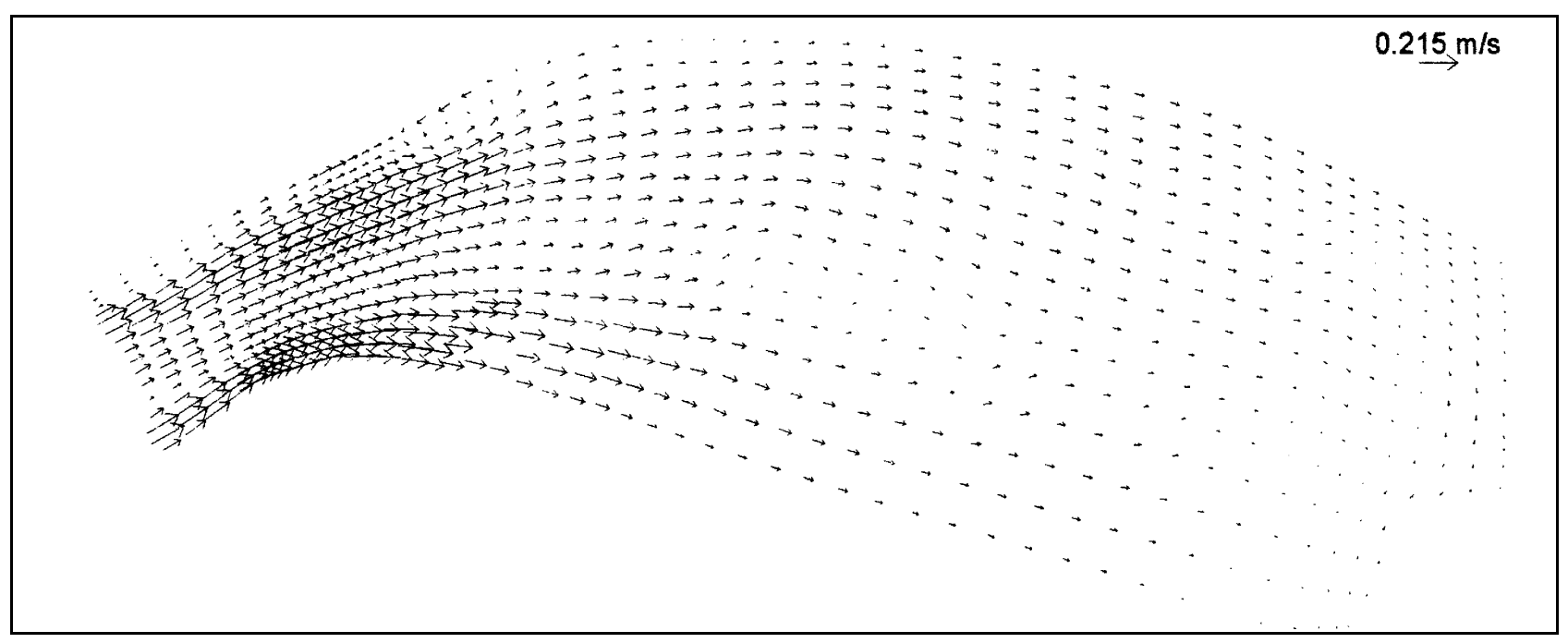

Figura 7. Configuração dos Vetores Velocidade no instante 11.

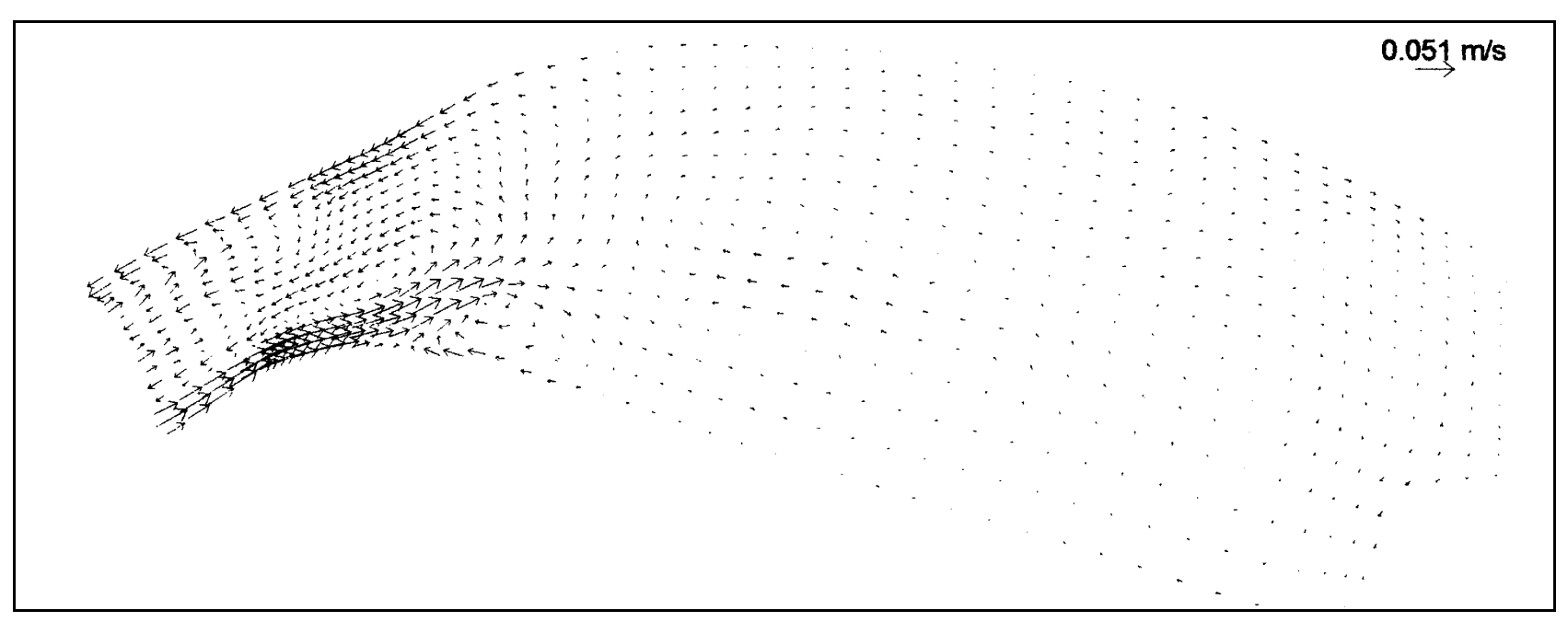

Figura 8. Configuração dos Vetores Velocidade no instante 1.

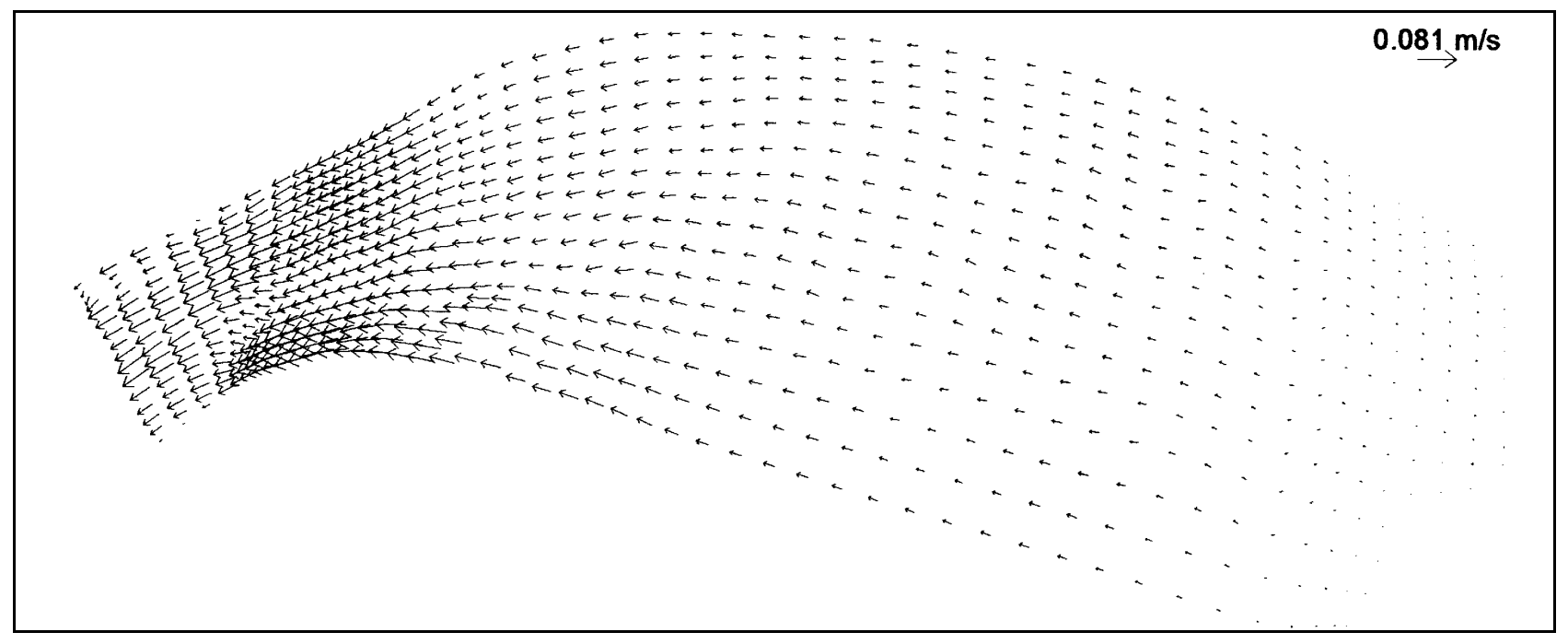

Figura 9. Configuração dos Vetores Velocidade no instante 4. 
No instante 8, indicado na Figura 10, o sentido do fluxo se inverte em toda a bacia.

No instante 11, indicado na Figura 11, notase uma redução da advecção na bacia.

No instante 13 também ocorreu um padrão de fluxo assemelhado ao do instante 1 , indicado na Figura 8.

Simulação das elevações - As elevações produzidas na bacia pelas amplitudes testadas neste estudo apresentaram variações muito suaves, apenas com o auxílio de uma escala adequada foi possível verificar variações espaciais no comportamento das elevações no corpo d'água. Este resultado parece ser consistente com os valores absolutos das amplitudes testadas, o período, a batimetria e a geometria do corpo d'água.

\section{Validação dos resultados do modelo}

Para validar um modelo matemático podese comparar os seus resultados com soluções analíticas, resultados de outros modelos, ou com medidas efetuadas em modelos físicos ou na natureza. Na prática, a validação depende especialmente da existência de resultados experimentais e numéricos confiáveis, dado que as soluções analíticas só existem para um número escasso de casos relativamente simples.

Com o objetivo de validar os resultados do modelo hidrodinâmico foram comparados seus valores calculados de elevações com os observados (medidos em campo). Dentre as medições de nível realizadas, foi selecionada, para verificação do modelo, a do dia 15 de agosto de 1996 estando a

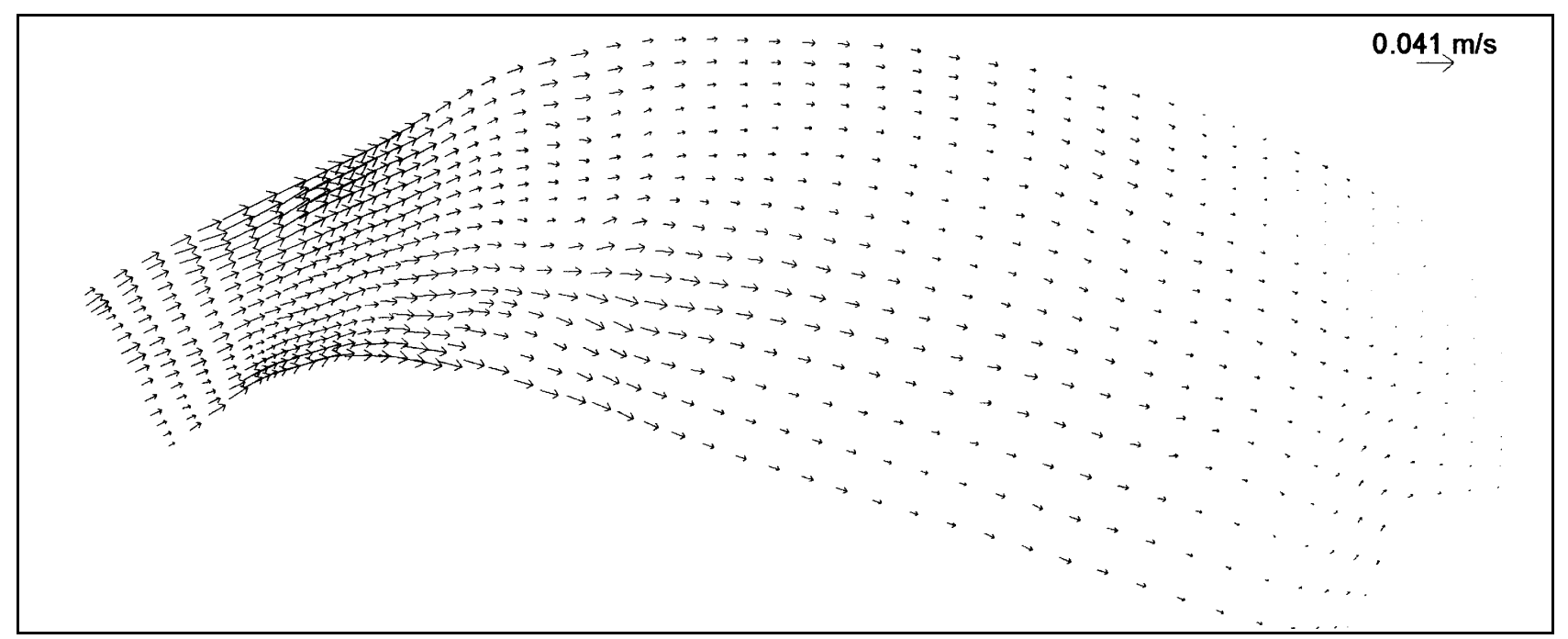

Figura 10. Configuração dos Vetores Velocidade no instante 8.

Figura 11. Configuração dos Vetores Velocidade no instante 11. 
maré, neste dia, em situação de sizígia. Tal escolha deveu-se ao fato da batimetria utilizada na simulação em computador (Figura 3) ter sido obtida com mapa batimétrico em regime de baixa-mar de sizígia e por apresentar amplitude de maré $(2.1 \mathrm{~m})$ aproximada da considerada no computador $(2.2 \mathrm{~m})$.

O procedimento utilizado baseou-se em leituras de níveis d'água num local da bacia do Pina de fácil acesso para instalação e leitura de régua (Figura 1), durante um ciclo completo da maré. Cada valor de variação de elevação é obtido por meio da subtração das leituras de régua entre instantes consecutivos. O gráfico mostrado na Figura 12 revela em forma comparativa os resultados da simulação em computador e os medidos em campo.

Pela observação do gráfico pode-se constatar uma boa concordância entre os resultados obtidos com o modelo e os medidos em campo para a elevação da maré.

\section{MODELO DE TRANSPORTE}

\section{Metodologia utilizada}

Uma vez calculado o campo de escoamento, ou seja, uma função vetorial que a cada ponto do plano (2D) associa em cada instante de tempo um vetor velocidade, foi feita a investigação (simulação) do transporte resultante de lançamentos permanentes de uma substância contaminante.

Com as informações de velocidades e elevações (profundidades atuais) calculadas pelo modelo hidrodinâmico, o modelo de transporte é alimentado pelo sistema computacional, visando caracterizar o transporte hidrodinâmico induzido pela ação das marés.

O modelo matemático usado para o transporte fluido é coerente com as idéias do modelo de circulação turbulenta de larga escala, proposto em Rosman e Gobbi (1990), que simplificado (sem os termos de filtragem) fica, Araújo (1993):

$$
\frac{\partial \mathrm{C}}{\partial \mathrm{t}}+\mathrm{U}_{\mathrm{i}} \frac{\partial \mathrm{C}}{\partial \mathrm{x}_{\mathrm{i}}}=\frac{1}{\mathrm{H}} \frac{\partial}{\partial \mathrm{x}_{\mathrm{i}}}\left\{\mathrm{H}\left[\mathrm{D}_{\mathrm{i}_{\mathrm{j}}} \frac{\partial \mathrm{C}}{\partial \mathrm{x}_{\mathrm{j}}}\right]\right\}+\mathrm{G}
$$

onde C - concentração média na profundidade da substância em estudo, $D_{i j}$ - tensor dos coeficientes de difusividade turbulenta horizontal e G - termo de reação ou fontes/sumidouros promediado na profundidade.
A caracterização do fenômeno de transporte será possível com a prescrição de adequadas condições iniciais e de contorno das concentrações de um contaminante hipotético arbitrário e a posterior análise dos padrões de concentrações desenvolvidas com o tempo pelo modelo de transporte. Esta metodologia é similar a um estudo de simulação numérica de transporte de traçador, que é comumente usado como apoio às técnicas de campo utilizadas para avaliar as capacidades de renovação e de troca das águas em corpos d'água naturais, conforme Nece et al. (1980). Os resultados do estudo numérico com traçador também podem fornecer mais informações sobre o transporte e a circulação dinâmica dos corpos d'água do que aqueles baseados apenas na plotagem dos vetores velocidade calculados pelo modelo hidrodinâmico. O contaminante representado pelas simulações é arbitrário, sendo sua principal hipótese a de ser passivo (traçador). Também foi assumido que não ocorrem reações químicas ou biológicas entre o contaminante e a água. Dessa forma, os resultados são estritamente representativos das características do transporte fluido (hidrodinâmico) das massas d'água na bacia.

\section{Dados do problema}

Para a discretização espacial tomou-se como base de pontos (nós) a malha de elementos finitos usada no modelo hidrodinâmico. Como a versão atual do modelo de transporte usa elementos finitos triangulares lineares, a malha para o transporte resultou com 408 elementos (cada elemento é transformado em 8), para os mesmos 239 nós. A Figura 13 mostra a malha de discretização resultante usada no modelo de transporte (malha triangular).

Comparando-se as Figuras 2 e 13, tem-se a impressão visual da Figura 13 ser uma malha bem mais refinada. Isto é verdade no sentido gráfico, devido à diminuição dos elementos finitos considerados e a conseqüente maior densidade gráfica de traços, no entanto do ponto de vista do potencial da ordem de precisão dos resultados, o da Figura 2 é quadrático enquanto que o da Figura 13 é linear, conforme discutido em Araújo (1993). Esta malha apresenta uma distância máxima entre nós de 210 m e mínima de $30 \mathrm{~m}$.

Face à falta de dados de campo, os coeficientes de difusividade turbulenta horizontal nesta aplicação exploratória, foram admitidos constantes e iguais $\left(D x x=D y y=4 \mathrm{~m}^{2} / \mathrm{s}\right.$ ) em todo o domínio computacional. $\mathrm{O}$ valor numérico associado foi es- 


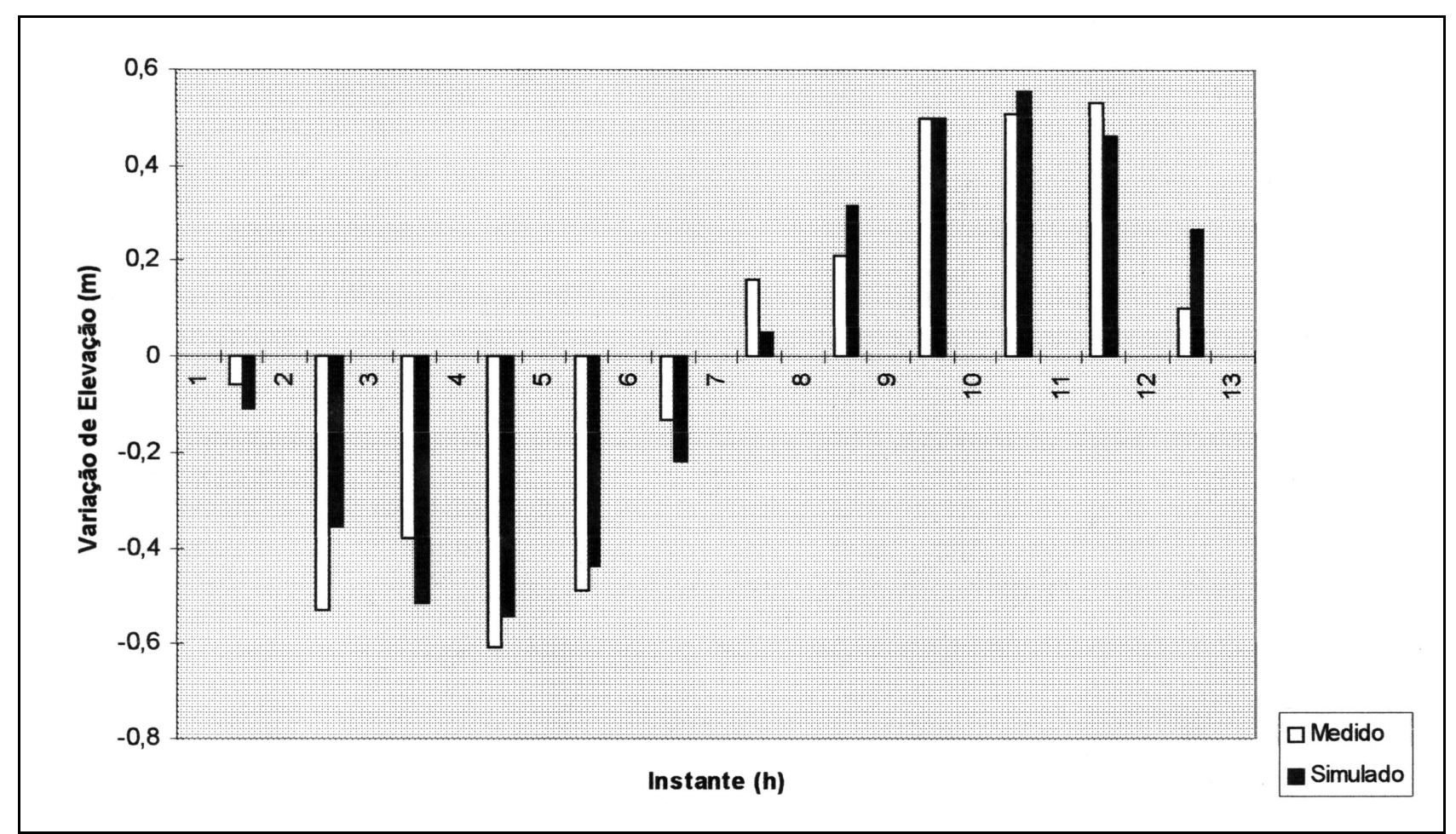

Figura 12. Validação das elevações.

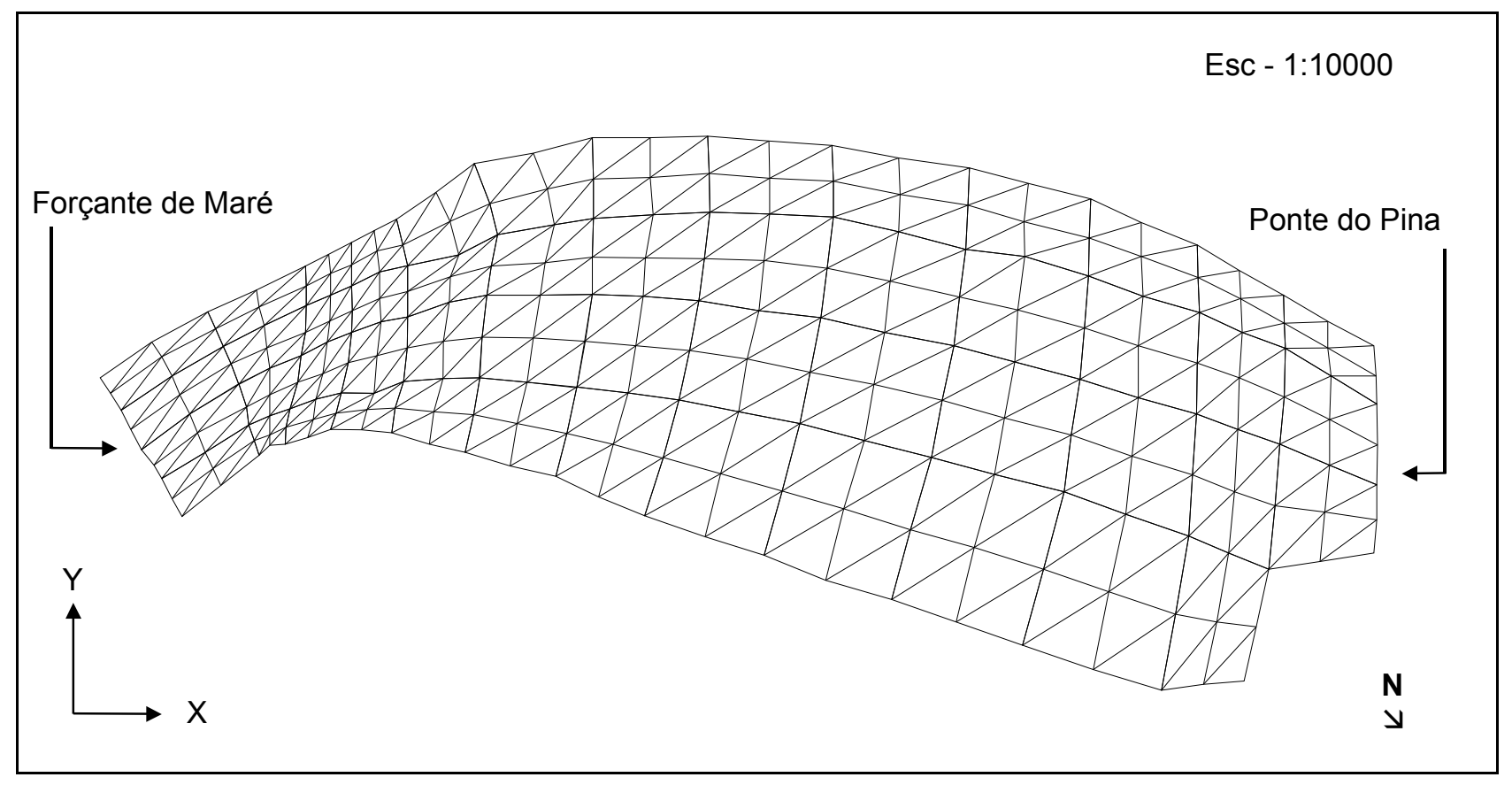

Figura 13. Discretização de elementos finitos triangulares.

colhido de modo a garantir a estabilidade numérica no processo de cálculo. Nesse caso, o número de Peclet nodal máximo possível seria em torno de 11 e um valor médio seria de 0.75 . Adotou-se o valor $\mathrm{C}(\mathrm{x}, \mathrm{y}, \mathrm{t}=0)=0$, para indicar a concentração inicial do traçador arbitrário pré-existente na bacia.

Como para a bacia do Pina podem afluir contaminantes originários seja da bacia portuária (região da garganta) por efeito de marés, ou 
da foz comum via Ponte do Pina, simulou-se distintos padrões de espalhamento de um hipotético efluente contaminante localizado nesses dois contornos.

No primeiro caso, existem 9 nós no contorno aberto e, no segundo caso, 7 nós. Neles são especificadas condições essenciais ou Dirichlet $(C=100)$ o que equivale a uma concentração de referência de $100 \%$ permanente.

Os demais nós, ao longo do contorno fechado da bacia, formam lados onde são prescritas condições naturais (Neumann) indicativas de fluxo difusivo de massa do traçador nulo, na direção normal ao lado considerado.

\section{Resultados}

Para apresentação dos resultados em cada caso de lançamento, adotou-se dois instantes de tempo para as duas amplitudes de estudo, representando situações de preamar e de nível d’água médio, respectivamente.

\section{Lançamento: bacia portuária}

Entre os dez períodos de maré da simulação considerada adotou-se o quarto, já que acima deste, as concentrações calculadas já atingiam valores muito acima de $100 \%$ em alguns locais, provavelmente por conta de se tratar da simulação de um contaminante conservativo e das condições de contorno de fluxo nulo impostas ao problema pela outra fronteira (Ponte do Pina)

Maré de sizígia - No instante 1 os locais de maiores concentrações estão espalhados desde a região da garganta até a parte central da bacia principal, podendo-se notar que a frente de poluente, com concentração de valor $80 \%$, se propaga de modo mais acentuado pela margem superior da Figura 14.

$\mathrm{Na}$ Figura 15, correspondente ao instante 4, nota-se um recuo da frente de propagação de maneira mais acentuada no centro e na margem inferior da mesma, causado pelo aumento da advecção revelado na Figura 5.

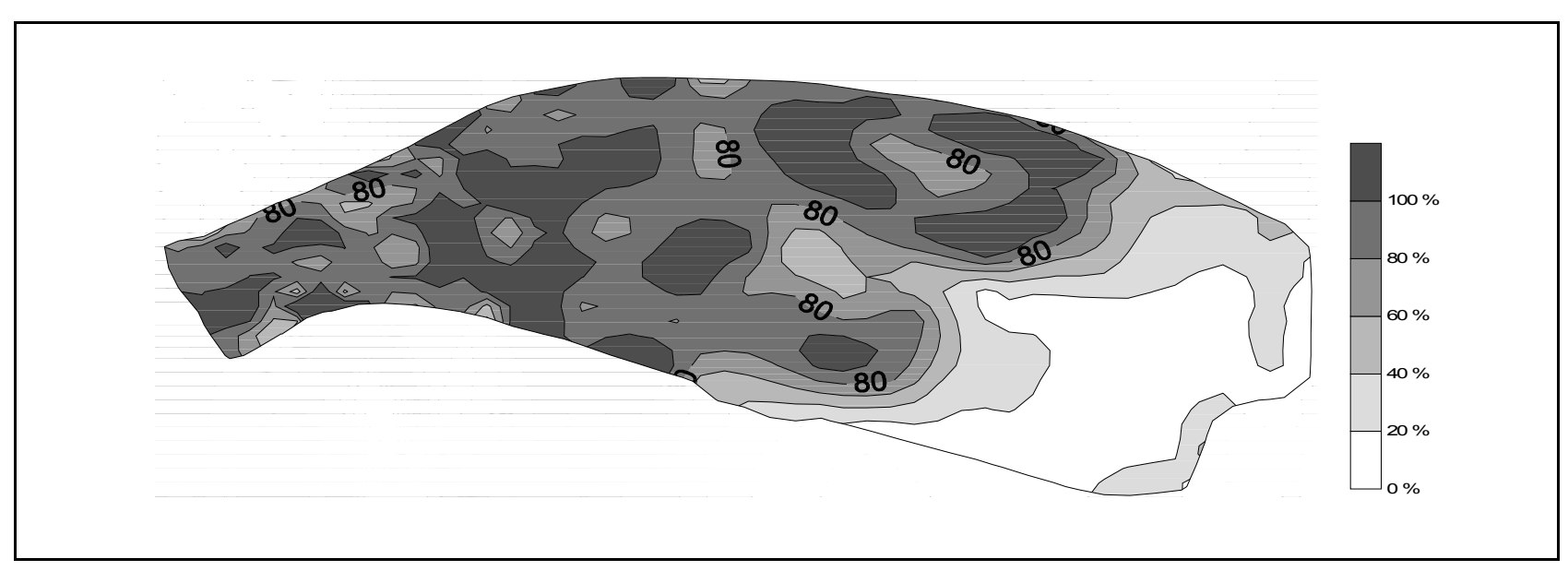

Figura 14. Configuração das concentrações no instante 1.

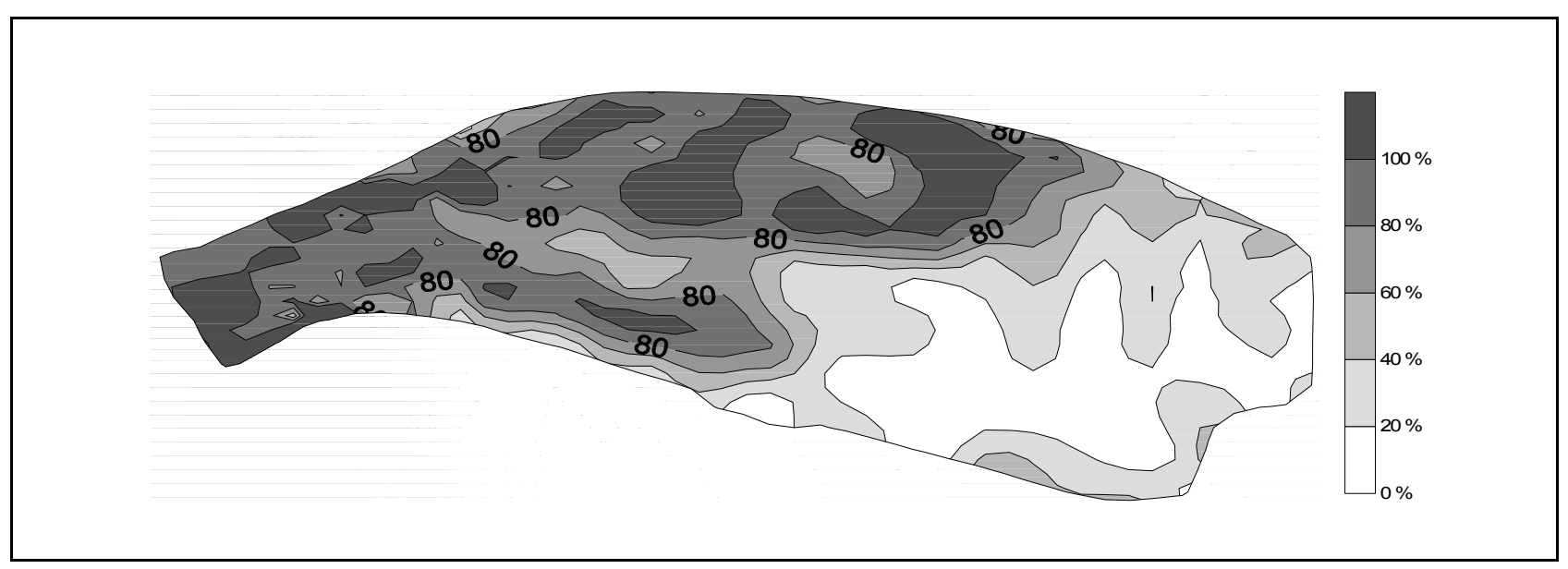

Figura 15. Configuração das concentrações no instante 4. 
Quadratura - Nesta maré, a frente de poluente no instante 1, com concentração de valor $80 \%$ mostrado na Figura 16, já não atinge mais a bacia principal, estando os locais de maiores concentrações situados na região da garganta.

$\mathrm{Na}$ Figura 17 correspondente ao instante 4, nota-se um recuo da frente de poluente associado a uma menor difusão comparativamente ao instante 1, causada pelos efeitos advectivos indicados na Figura 9.

\section{Lançamento: Ponte do Pina}

Em vista da condição de contorno de fluxo nulo imposta ao problema na fronteira correspondente à Ponte do Pina, o processo de espalhamento do contaminante a partir desta seção é comandado principalmente pelo processo de difusão.

Maré de sizígia - No instante 1 , a nuvem de poluente remanescente do período anterior ao mostrado, com concentração de valor $30 \%$, localizada no lado esquerdo inferior da Figura 18, praticamente desaparece no instante 4 , conforme mostra a Figura 19, evidenciando o fenômeno de "flushing", isto é, a renovação das águas da bacia pela região da garganta onde está induzido o efeito de maré. No contorno correspondente ao lançamento (Ponte do Pina) observa-se um lento processo de espalhamento da mancha contaminante explicado pela lentidão do processo difusivo. $\mathrm{Na}$ margem direita inferior da Figura 19, pode-se notar um avanço relativo da mancha de $10 \%$ em concordância com o aumento local de advecção constatado entre as Figuras 4 e 5.

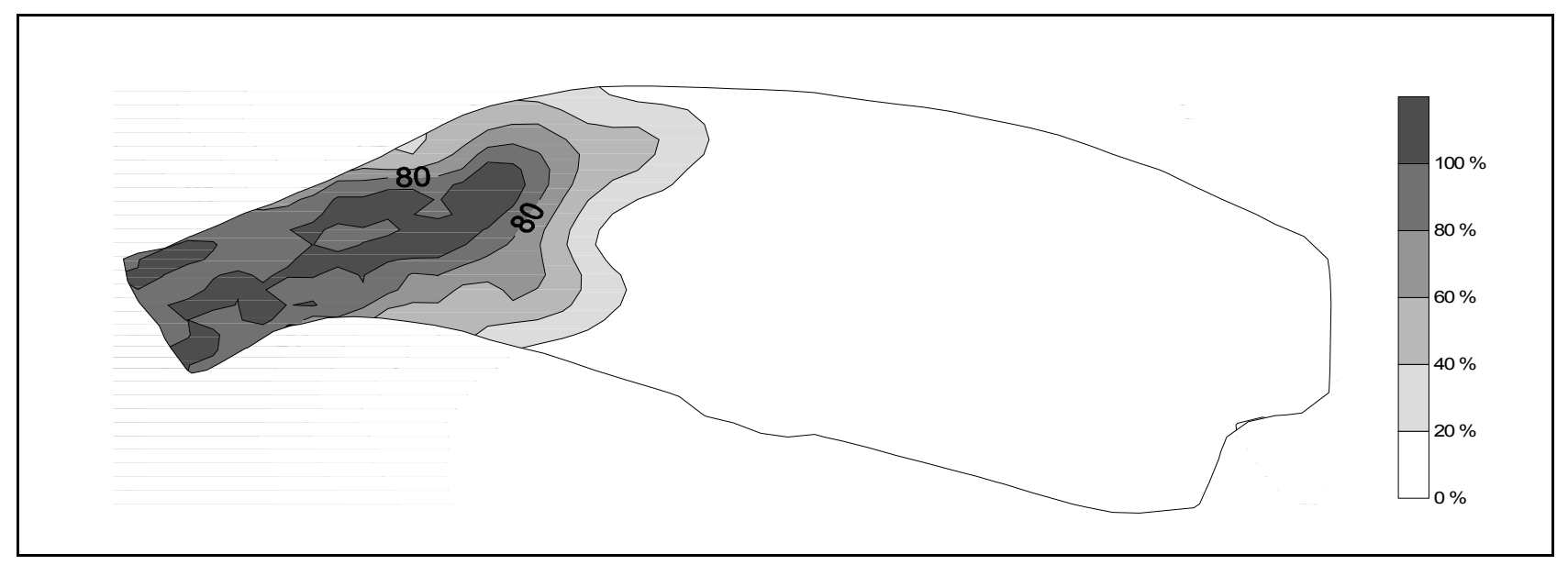

Figura 16. Configuração das concentrações no instante 1.

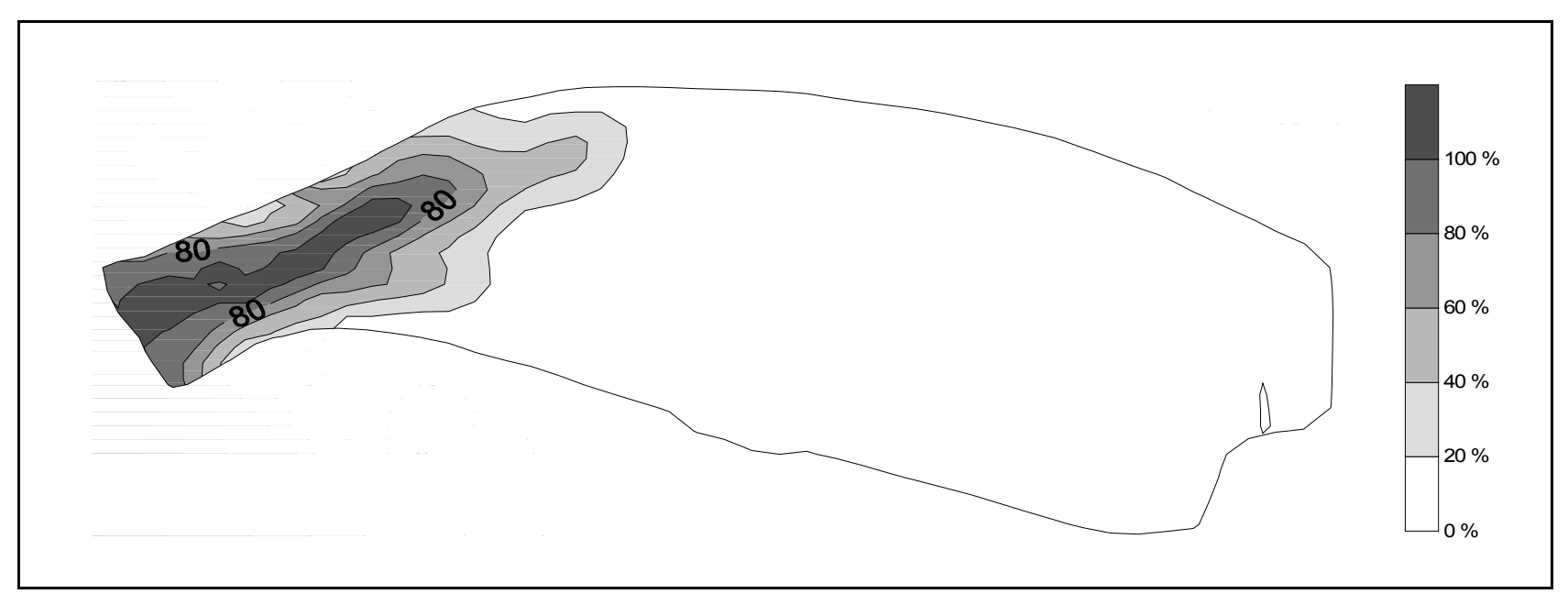

Figura 17. Configuração das concentrações no instante 4. 


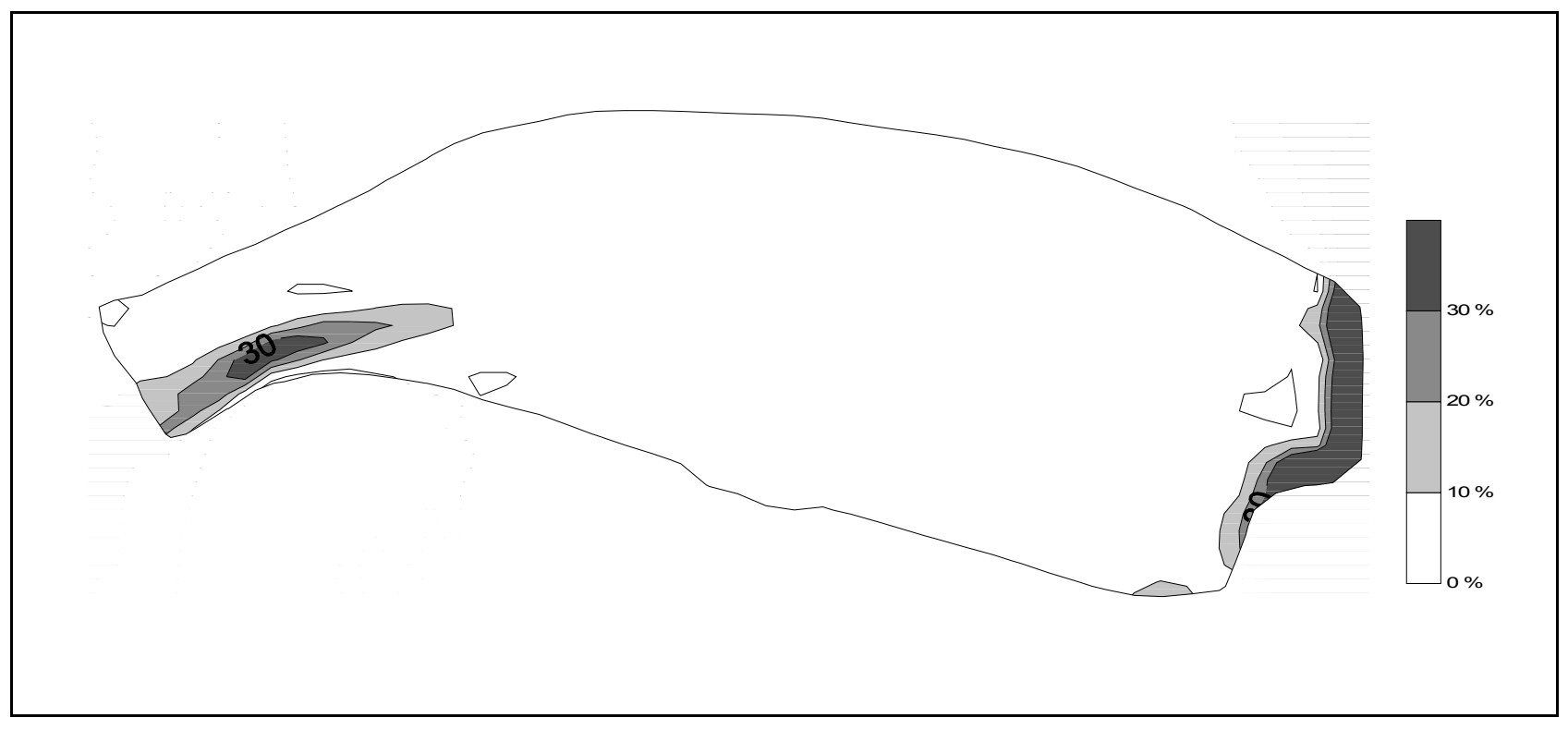

Figura 18. Configuração das concentrações no instante 1.

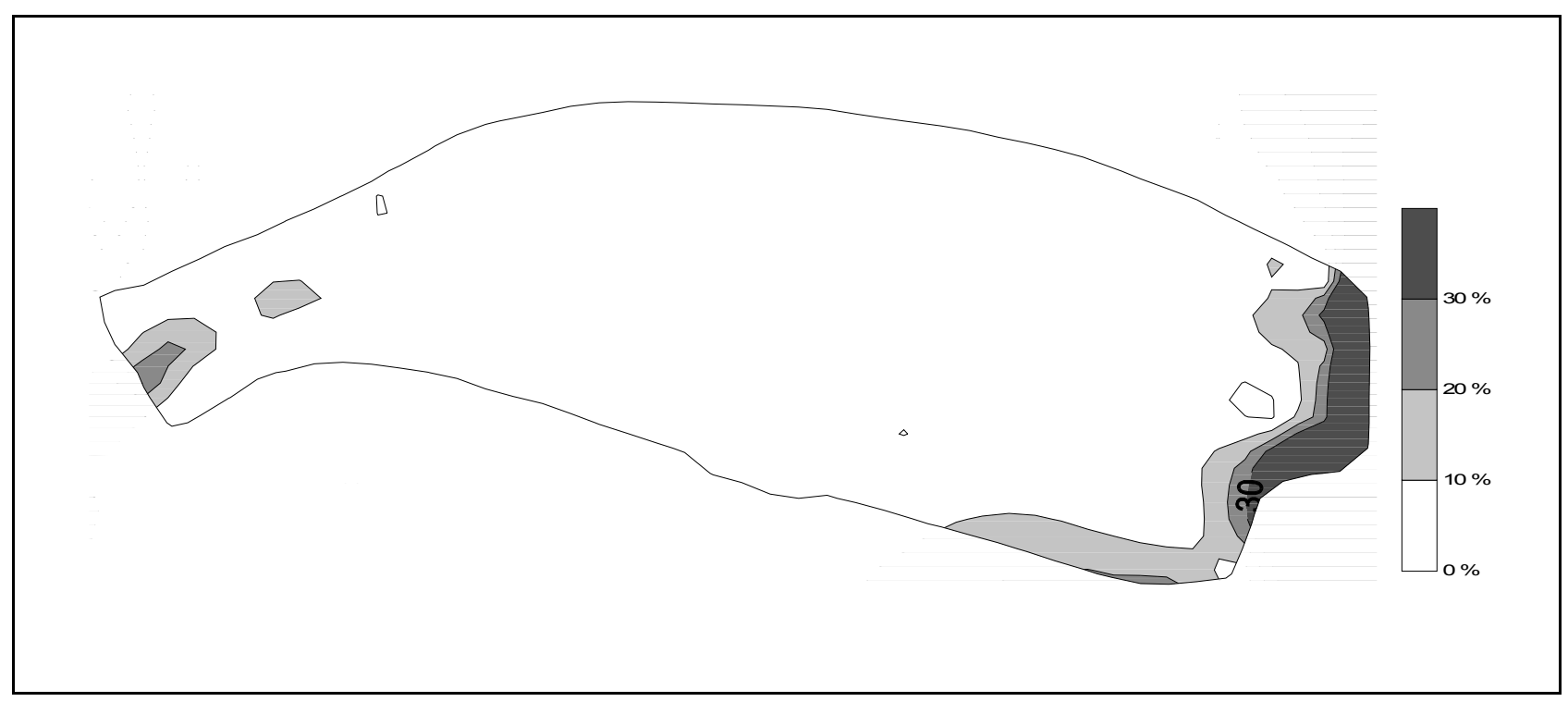

Figura 19. Configuração das concentrações no instante 4.

Maré de quadratura - Estas marés, cujas amplitudes são induzidas via bacia portuária, resultaram num grau de espalhamento muito fraco pela bacia proveniente de hipotético lançamento feito pela Ponte do Pina. Durante todo o período de estudo, percebeu-se apenas uma configuração contínua de valores de concentração cujas isolinhas se encontram pouco adiante do local de lançamento. Isto pode ser explicado pela baixa capacidade de advecção nas imediações do local de lançamento conforme sugerem as Figuras 8, 9, 10 e 11 da circulação hidrodinâmica.

\section{CONCLUSÕES}

A modelagem da qualidade da água trata com sistemas possuindo complexas interações entre processos físicos, químicos e biológicos, nos quais a circulação da água é o mais importante fator de controle desses processos.

A prática da moderna engenharia tem demandado nos últimos anos a elaboração de estudos e projetos técnicos, que desenhem cenários alternativos baseados em previsões quantitativas das possíveis novas situações da 
qualidade das águas, quando submetidas a algum tipo de intervenção que possa trazer impacto ambiental.

A forma em planta da geometria e a batimetria da bacia do Pina têm um efeito significativo no seu padrão de circulação. Tais características são úteis na eliminação de poluentes, como por exemplo o estreitamento e a brusca mudança da batimetria na região da garganta, gerando um efeito de jato que contribui para a promoção da circulação na bacia e para o seu "flushing".

Nos resultados do modelo hidrodinâmico, o surgimento de células de circulação na bacia principal, assim como padrões de escoamento turbulentos na garganta, por ocasião da baixa-mar, pode ser explicada pela irregularidade acentuada da batimetria usada.

No modelo de transporte, a configuração dos resultados obtidos, no caso de lançamento pela bacia portuária, mostrou um grau de espalhamento intenso em comparação com os resultados dos lançamentos pela Ponte do Pina, explicado pela ação dinâmica (advectiva) das marés. Foi possível ainda constatar-se em outras situações, correlação entre os resultados advectivos do modelo hidrodinâmico com o espalhamento obtido com o modelo de transporte.

O sistema computacional utilizado revelou resultados exploratórios encorajadores, devendo ser aplicado em outras ocasiões, com um conjunto de dados mais consistentes e atualizados, tornando-se assim uma ferramenta para uso prático na gestão ambiental, especificamente na previsão dos padrões de circulação e transporte das águas da bacia do Pina.

\section{AGRADECIMENTOS}

Agradecemos ao CNPq pela concessão de auxílio financeiro e bolsa de iniciação científica ao segundo autor no projeto Al 520327/95-0 "Simulação dos processos de transporte de poluentes líquidos em rios estuarinos do Recife".

\section{REFERÊNCIAS}

ABBOT, M. B. e BASCO, D. R. 1989. Computational Fluid Dynamics: An introduction for engineers - Longman Scientific \& Technical.

ARAÚJO, A. M., MEDEIROS J. G. M. 1992. Simulação numérica da circulação e transporte hidrodinâmico em marinas. Efeitos de suas formas em planta. Simpósio de Recursos
Hídricos do Nordeste, Anais, vol. I, p.145-154, artigo completo.

ARAÚJO, A. M. 1993. Um sistema computacional para simulação do escoamento e transporte fluido turbulentos em corpos d'água rasos usando técnicas de filtragem. Dissertação de Doutorado. COPPE/UFRJ, Rio de Janeiro, $136 p$.

BORCHE, A. 1996. IPH-A Aplicativo para Modelação de Estuários e Lagoas, IPH UFRGS Porto Alegre.

FEITOSA, F. A. N. 1988. Produção primária do fitoplâncton correlacionada com parâmetros bióticos na Bacia do Pina (PE). Dissertação de Mestrado. UFPE, Recife, 270p.

NECE, R. E., SMITH, H. N. e RICHEY, E. P. 1980. Tidal calculations and flushing in five western Washington marinas. Charles W. Harris Hydr. Lab., Tech. Report No. 63, Univ. of Washington, Seattle, Wash.

NEVES, R. J. 1985. Étude experimentale et modélisation Mathématique des circulations transitoire et résiduelle dans 1' Estuaire du Sado. Ph.D Thesis, Université de Liége, Belgique.

ROSMAN, P. C. C., GOBBI, E. F. 1990. A selfadjusting subgrid "turbulence" model for shallow water flow. XI Congresso Íbero Latino Americano sobre Métodos Computacionais para Engenharia.

ROSMAN, P. C. C. 1987. Modelling shallow water bodies via filtering techniques. Ph.D Thesis, MIT, USA. 


\section{Exploratory Simulation of Tidal \\ Effects on Circulation and \\ Hydrodynamic Transport in the \\ Pina Basin}

\section{ABSTRACT}

A two-dimensional computational system, integrated over depth, was adapted and developed by GMF/UFPE as a means of simulating circulation and associated hydrodynamic transport induced by tides in the Pina basin, part of the estuarine system of the city of Recife, Pernambuco State. The purpose of the study was to evaluate the changes, still at the exploratory stage, in the circulation and transport patterns caused by different tidal amplitudes (sizigy and quadrature). All simulations predicted velocity and transport fields at thirteen time intervals of one hour, produced for a complete cycle of the corresponding tide. As a general qualitative result, configurations of hydrodynamic circulation were obtained which showed basin inflows and outflows in accordance with tidal state. In the simulation of hydrodynamic transport, the general form of results was obtained assuming a fictitious pollutant released at the leading edge of the tide. The model then showed the development of small areas of high concentration, resulting the strong dispersive action of the tide, compared with the more even dispersal when the fictitious pollutant was released at the tidal state corresponding to zero flux. 